\title{
OS PROCESSOS DE AQUISIÇÃO DOS TERMOS DO SILOGISMO SEGUNDO A INVESTIGAÇÃO NOÉTICA DE AVICENA
}

\author{
Meline Costa Sousa* \\ melinecostasousa@hotmail.com
}

RESUMO Tendo em vista o desacordo entre os comentadores contemporâneos acerca do modo pelo qual o intelecto teorético conhece no "Kitāb al-nafs" de Avicena, investigo se esta atividade se realiza por um sentido interno que é auxiliado pelo intelecto a fim de abstrair a forma material ou se é uma atividade exclusiva do intelecto que não depende das formas materiais, mas apenas da intuição das formas inteligiveis. Contudo, algumas passagens das seções V.5 e V.6, nas quais são descritas a atividade conjunta entre intelecto e os sentidos internos e a sua atividade própria, conduzem à conclusão segundo a qual são necessários dois elementos para que o conhecimento seja realizado: a unificação da multiplicidade e a multiplicação da unidade; em outras palavras, não é suficiente que o intelecto, em conjunto com as faculdades estimativa e cogitativa, conceitualize os termos menor e maior do silogismo, mas ele também precisa intuir o termo médio.

Palavras-chave Epistemologia, intelecto, filosofia medieval.

ABSTRACT There is a disagreement among contemporary commentators about Avicena's view of the theoretical intellect in "Kitäb alnafs". Is its activity performed by an internal sense helped by the intellect, or is it a activity proper of the intellect independently of material forms?

* Doutoranda em Filosofia pela UFMG/CAPES. Artigo recebido em 21/05/2014 e aprovado em 06/08/2014. 
Some passages of V.5 and V.6 suggest that both elements are necessary to the knowledge: unifying the multiplicity and multiplying the unity; in others words, it is not enough that the intellect conceptualizes the minor and major terms of the syllogism, it also needs to intuit the middle term.

Keywords Epistemology, Intellect, Medieval Philosophy.

Avicena dedicou parte das suas investigações naturais ou físicas à alma e ao modo pelo qual uma das suas atividades mais essenciais, a dizer, o conhecimento teorético, é realizado, sendo a sua atividade mais essencial a autointelecção. ${ }^{1}$ Embora o filósofo as tenha abordado em diferentes obras ao longo da sua vida, é no "Kitāb al-nafs" da "Shifā",, 2 traduzido para o latim como "De anima", onde se encontra um exaustivo estudo das faculdades da alma. O fio condutor das suas cinco seções é a busca por aquela que seria a atividade própria de cada uma das faculdades tendo em vista não apenas o propósito fundamental, a partir do qual há uma ação exclusiva para cada uma delas, como também a posse (ou não) de um órgão apto.

No que toca ao seu quinto livro, inteiramente dedicado ao intelecto e à sua relação com as outras faculdades da alma, Avicena não se preocupa em detalhar alguns pontos com os quais se depara ao longo das seções como, por exemplo, o que são o assentimento e a conceitualização ou o porquê da distinção ontológica entre o intelecto humano e o intelecto agente. Isto se justifica dada a inserção da obra no interior da filosofia natural. Partindo do postulado ${ }^{3}$ segundo o qual não cabe a uma ciência demonstrar seus próprios princípios, Avicena adota o procedimento da constatação (ìthbat) como modo de começar seus raciocínios sem ter que, ad infinitum, demonstrar os princípios das demonstrações e, assim, os princípios dos princípios...

1 Avicena apresenta, no "Kitāb al-nafs" I.1 e V.7, duas versões do experimento mental do homem suspenso no ar a fim de apontar que o homem é capaz de realizar a atividade de inteligir sua própria existência (autointelecção) de modo independente do corpo e das faculdades corpóreas. Cf. A. R. D. Alwishah, 2006; R. Arnaldez, 1972; D. Black, 2012; D. Black, 2008; A. Hasnawi, 1987; M. Marmura, 1986; S. Westra, 1992.

O "K. al-shifā"” (Livro da cura) foi composto por Avicena na primeira metade do século XI, entre 1020-7. Ele é dividido em lógica, física, matemática e metafísica, sendo o "K. al-nafs" o quinto livro que compõe a parte dedicada à física. Este se divide em cinco livros. O primeiro fornece a prova da existência da alma, a sua definição geral, uma primeira indicação da sua substancialidade e independência do corpo e, por fim, uma classificação e investigação de algumas das suas funções. O segundo livro se inicia com uma análise das ações próprias da alma vegetal e, em seguida, passa ao estudo das faculdades da percepção, encerrando com a análise de quatro dos cinco sentidos externos. O terceiro livro é inteiramente dedicado ao quinto sentido externo, a visão. O quarto livro trata dos sentidos internos, dos critérios a partir dos quais eles são diferenciados e das ações peculiares a cada um deles. O quinto livro investiga as ações próprias da faculdade racional da alma.

3 Cf. A. Bertolacci, 2007, pp. 61-98. 
Neste sentido, a compreensão da abordagem epistemológica proposta no "Kitāb al-nafs" deve levar em consideração o fato de alguns dos seus raciocínios ${ }^{5}$ apresentarem limites peculiares ao âmbito de investigação no qual a obra se encontra, os quais, por vezes, podem não satisfazer as curiosidades do leitor. Tendo isto em vista, a interpretação que proponho dos processos pelos quais o intelecto adquire os termos do silogismo se baseia nas seções V.3, V.5 e V.6 desta obra e, na tentativa de explicitar certos pressupostos tomados pelo filósofo, recorrerei a algumas considerações lógicas e metafísicas.

Otextoquese seguedividir-se-áem dois grandesmomentos.Primeiramente, após apontar a insuficiência da afirmação segundo a qual o intelecto conhece por abstração das formas materiais, mostrarei como o conhecimento que se realiza através do pensamento possui uma estrutura silogística. Alguns exemplos de premissas apontam que os termos maior e menor do silogismo são adquiridos por conceitualização. Contudo, conceitualizar os particulares que se encontram na imaginação não é suficiente para produzir conhecimento. Para isto, é necessário que o intelecto intua o termo médio do silogismo e, assim, seja capaz de assentir o conteúdo das premissas.

Tendo esclarecido como tudo isto se dá, argumentarei contra a posição que nega qualquer tipo de participação dos particulares e, consequentemente, dos sentidos internos na produção do conhecimento. Disto resulta a redução do conhecimento à intuição (hads) das formas inteligíveis que se encontram no intelecto agente. Esta interpretação baseia-se na afirmação aviceniana de que a atividade de conhecer se mantém mesmo após a morte de modo a ser realizada apenas por uma faculdade incorpórea que não sucumbe com a morte do corpo. Assim, a intuição enquanto processo de recepção não mediada dos inteligíveis responderia perfeitamente às necessidades póstumas da alma. Argumentarei, recorrendo a alguns exemplos de silogismos, que determinados termos das premissas apenas são fornecidos ao intelecto pelos sentidos internos.

O segundo momento deste artigo se inicia com a análise de um exemplo de silogismo demonstrativo apresentado por Avicena no "Kitāb al-burhan" (Livro das demonstrações). A partir dele e de uma passagem do "K. al-nafs", apontarei as duas etapas que compõem o ato de conhecer e que são fundamentais para a compreensão tanto da influência dos sentidos internos quanto da ação que somente se realiza pelo intelecto. Indicarei os problemas de afirmar que o 
pensamento, responsável por produzir um dos tipos de conhecimento descrito em V.5, é a atividade conjunta entre o intelecto e faculdade cogitativa. Para isto, valer-me-ei dos critérios de classificação das faculdades perceptivas e dos argumentos contra a materialidade do intelecto apresentados em V.2.

Contra estas diferentes abordagens da epistemologia de Avicena, defenderei que o pensamento depende da intuição dos termos médios do silogismo para produzir conhecimento. Há, portanto, uma ação conjunta entre o intelecto e os sentidos internos de unificar a multiplicidade e uma ação própria do intelecto de multiplicar a unidade.

\section{I}

O conhecimento ( 'ilm) é a atividade própria do intelecto teorético de modo a caber apenas a esta faculdade "a extração dos universais simples a partir dos particulares por meio da abstração das suas intenções da matéria, das suas aderências da matéria e dos seus agregados [...]" (Avicena, "K. al-nafs", V. 3 , p. 220), chegando à forma universal desvinculada das qualidades sensíveis que a acompanham. No entanto, esta breve descrição de como o intelecto conhece não é suficiente para compreender o que é peculiar a ele e que o torna a única faculdade capaz de conhecer. Em geral, a abstração (tajrìd, intizā') é utilizada por Avicena para explicar a relação entre as faculdades perceptivas da alma, ou seja, os sentidos externos e internos, e as formas materiais. Ainda que haja variações de grau entre a abstração feita por eles e pelo intelecto, o termo é igualmente aplicado às atividades realizadas por todos eles.

Falaremos agora sobre as faculdades da sensibilidade e da percepção, sobre elas com um discurso universal. Dizemos: parece que toda percepção é, de um certo modo, a apreensão da forma percebida. Se a percepção é percepção de algo material, então ela é a apreensão da forma abstraída da matéria por certa abstração, [mas] os tipos de abstração são diferentes e os seus graus são muitos (Avicena, "K. al-nafs", II.2, p. 58).

Assim, a abstração está envolvida na descrição da relação entre as formas materiais e as faculdades da "sensibilidade e da percepção" (idem). Cada uma destas faculdades separa, a seu modo, a forma da matéria e dos acidentes que a acompanham. Trata-se não de uma explicação de como isto é feito, mas de uma descrição do que é feito. ${ }^{6}$ Por esta razão, não se aplica apenas ao

6 No "K. al-burhan" ("Livro das demonstrações"), Avicena associa a abstração realizada pelo intelecto à conceitualização: "se conceitualizar o homem no intelecto ao defini-lo estivesse vinculado a uma medida, posição ou algo similar, todo homem compartilharia [estas coisas]. Contudo, esta magnitude que se observa pelos sentidos, esta posição, este lugar, etc., vinculam-se ao homem apenas devido à matéria que lhe é particular. Assim, obviamente, na medida em que homem é conceitualizado no intelecto pela 
intelecto. Stricto sensu, conhecer não é abstrair formas materiais. Cabe, então, a fim de compreender o que o intelecto faz e que nenhuma outra faculdade sozinha consegue realizar, a investigação do modo pelo qual o conhecimento ('ilm) é produzido.

No "Kitāb. al-nafs" (Avicena, "K. al-nafs", V.6, p. 243) e na parte psicológica do "Dânesh-nâmè" (Avicena, "Le livre de science", pp. 23$24)^{7}$ uma importante distinção é inserida em vista dos dois modos pelos quais o conhecimento se realiza. Avicena nomeia-os como conhecimento pelo pensamento ('ilm al-fikr) e conhecimento simples (al-'ilm al-basit t). A característica do primeiro é o fato de que "[sua] plena perfeição se completa ao ordenar e compor [formas]" (Avicena, "K. al-nafs", V.6, p. 243) de modo que as formas são articuladas uma a uma em proposições. O segundo, o conhecimento simples, é marcado pela ausência de composição das formas, produzido instantaneamente no intelecto. Embora Avicena não forneça mais informações acerca da natureza deste segundo tipo de conhecimento, no "Dânesh-nâmè", ele será associado ao conhecimento dos primeiros princípios como, por exemplo, "que duas coisas iguais a uma terceira são iguais entre si" (Avicena, "Le livre de science", p. 23).

Sobre as origens desta distinção, é no "Segundos analíticos" 100b618 (Aristóteles, "Kitāb al-burhan", p. 619) que Aristóteles distingue entre o conhecimento acompanhado de raciocínio e o conhecimento dos princípios para o qual não há raciocínio. Embora não seja dito, em detalhes, como este segundo modo se realiza, Aristóteles considera se tratar do conhecimento dos princípios que acontece apenas por intelecção ( $a q l / v o \bar{v} \varsigma$ ). Segundo o seu argumento, apenas o conhecimento [demonstrativo] e a intelecção são sempre verdadeiros; o conhecimento [demonstrativo] é acompanhado de raciocínio e o conhecimento dos primeiros princípios não é; logo, o conhecimento dos primeiros princípios não se dá por meio do conhecimento demonstrativo, mas por meio da intelecção. Como Ibn Yunus, tradutor dos "Segundos analíticos" de Aristóteles, bem reconheceu, o que está em jogo aqui é a distinção entre dois tipos de conhecimento, "já que o princípio do conhecimento também é conhecimento" (Aristóteles, "Kitāb al-burhan”, p. 619).

Voltando à distinção aviceniana, cuja origem se remonta à distinção aristotélica, no caso do conhecimento produzido pelo pensamento, para ser

definição, é algo abstraído pelo intelecto da matéria e dos seus acidentes e, como tal, não é algo que possa ser obtido pela percepção sensível" (Avicena, "Book of demonstrations", pp. 154-3).

7 Esta distinção também se encontra no "Compêndio sobre a alma". Cf. Avicena, "Compêndio", 8, §2. In: Gutas, 2013, p. 5. 
capaz de formular as premissas do silogismo, o intelecto precisa conceitualizar (tașawwuar) as formas materiais com o auxílio das faculdades cogitativa ${ }^{8}$ e estimativa. ${ }^{9}$ Tendo realizado a conceitualização, ${ }^{10}$ o intelecto é capaz de atribuir a intenção universal (ma 'na kullīa) ${ }^{11}$ "animal" à intenção "Zayd", ${ }^{12}$ por exemplo. Ainda com a ajuda da cogitativa e da estimativa, o intelecto formula proposições empíricas como "Zayd é animal" a fim de serem assentidas. ${ }^{13}$ Por mais que a intenção "animal" possa ser dita de qualquer uma das formas de homem que se encontram nos sentidos internos, ${ }^{14}$ em "Zayd é animal" ela é predicado de um indivíduo particular e não de todos os indivíduos da espécie. Por isto, a simples aquisição destas intenções não é suficiente para produzir conhecimento que, por princípio, ${ }^{15}$ é do universal e não do particular. Para que o intelecto conheça e chegue ao estágio de intelecto adquirido, ${ }^{16}$ é necessário que ele assinta (yaṣdaqu) a verdade da proposição "Zayd é animal" através da demonstração silogística. ${ }^{17}$ Como conhecer é conhecer a causa, o intelecto verifica que "Zayd é animal" após a aquisição do termo médio do

8 A faculdade cogitativa corresponde à imaginação compositiva nos animais. A diferença entre elas se deve à faculdade cogitativa estar sob o controle do intelecto, enquanto a compositiva realiza suas combinações de modo independente e, por isto, produz sonhos e devaneios. É esta última que distrai a inteligência, desviando-a das suas atividades próprias. Cf. D. Black, 2013, pp. 60-70.

9 Wolfson defende que as origens da faculdade estimativa podem ser remontadas a determinadas funções atribuídas à fantasia por Aristóteles. Deste modo, as necessidades que levaram a acrescentar outra faculdade ao grupo dos sentidos já presentes em Aristóteles não correspondem ao desejo de suprir uma deficiência, dado que a sugestão da existência de tal faculdade é feita pelo próprio Aristóteles ("Historia animalium" VIII.1, 588a, pp. 29-31); a faculdade da sagacidade, prudência e antecipação, que Aristóteles atribui aos animais, corresponde às descrições árabes e escolásticas de wahm e aestimatio (Cf. H. A. Wolfson, 1935).

10 Aqui faço um uso genérico do termo conceitualização. Avicena, em V.3, distingue três tipos de conceitualização. Segundo Black, trata-se da conceitualização em ato, da "memória intelectual", ou seja, da retomada de formas que já foram anteriormente conceitualizadas e, por fim, da conceitualização espontânea (Cf. Black, 2013, p. 74).

11 Existem dois tipos de intenção: própria ou material e comum ou universal. A primeira diz respeito à intenção apreendida a partir de um indivíduo singular, enquanto a segunda se refere à intenção que é atribuída a todos os membros da espécie (Cf. D. Black, 1993; C. Di Martino, 2006).

12 Ainda que o termo Zayd seja uma intenção obtida por conceitualização, ele não é universal, mas uma intenção particular. Trata-se de um nome que denota um indivíduo singular; ainda que possa ser dito de outro indivíduo, o seu sentido não será o mesmo, pois o Zayd dito de um e do outro é diferente na medida em que os indivíduos denotados são diferentes.

13 É através do silogismo que o intelecto assente ou verifica a verdade de uma proposição (Cf. Avicena, "Le livre de science", p. 48).

14 São cinco os sentidos internos: sentido comum, imaginação retentiva, imaginação cogitativa, estimativa e memória (Cf. C. Di Martino, 2008).

15 Cf. Aristóteles, "Kitāb al-burhan", pp. 516-526.

16 Cf. Avicena, "K. al-nafs", V.6, pp. 241-2; H. Davidson, 1992, pp. 86-8.

17 Tendo em vista os dois tipos de demonstração (burhān innā e burhān limā), neste caso, trata-se da burhān limā, pois é a investigação do porquê de tal fato. A conceitualização é responsável pelo intelecto conhecer o que algo é. Assim, a investigação do porquê fornece a causa de algo ser o que é (Cf. S. Arif, 2000, p. 101). 
silogismo, a causa. Embora os termos menor e maior sejam adquiridos por conceitualização, isto não pode ser dito do termo médio dada a sua natureza. ${ }^{18}$

Em outras palavras, tendo em vista esta estrutura silogística característica do conhecimento, o que não se aplica ao conhecimento simples, mas apenas ao conhecimento produzido pelo pensamento, o intelecto lida com termos que ocuparão a posição maior, média e menor no interior das premissas do silogismo. Contudo, há uma dificuldade que se apresenta com respeito a este segundo tipo de conhecimento. Como o termo médio do silogismo é princípio e causa da conclusão, ele não pode ser adquirido por nenhum processo de conceitualização, caso contrário, seria dividido em termos mais simples e assim estes termos serem os princípios e não ele. Poder-se-ia dizer, então, que este princípio também é obtido espontaneamente, ou seja, sem mediação dos sentidos internos? Aristóteles ("Kitāb al-hurhan", 89b10, p. 547) utiliza o

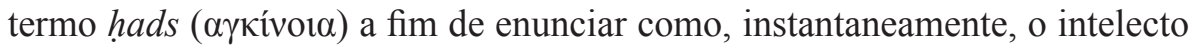
apreende o termo médio. Assim, não se trata do resultado nem de uma intelecção ( 'aql), nem de um pensamento ( $f i k r)$, mas de uma intuição.

Avicena ("K. al-nafs", V.6, pp. 248-9) mantém este modo de aquisição do termo médio mencionado por Aristóteles, acrescentando a ele uma nova opção. Em V.6, o critério para a distinção entre os modos de aquisição do termo médio é baseado na autossuficiência do intelecto, ou seja, trata-se de um processo mediado ou sem mediação: por um lado, o intelecto adquire o termo médio por si mesmo, ${ }^{19}$ o que é próprio da intuição; por outro, caso o intelecto não seja capaz de adquirir por si e precise de um professor que lhe forneça o termo médio, ele é obtido por aprendizado. No caso da intuição, por ser "uma ação própria da mente" (Avicena, "K. al-nafs", V.6, p. 249), ou melhor, "uma espontânea atividade do intelecto material" (Gutas, 1988, p. 171) que não necessita de um professor para conduzir o raciocínio, ela "acontece ao homem por ele mesmo e [ele] articula o silogismo em sua mente sem professor"

18 No "K. al-burhan", 84b 20-24, Aristóteles afirma a indispensabilidade dos termos médios sem os quais não existe demonstração. Conhecemos algo quando sabemos a causa, a qual responde pelo por quê. Enquanto causa, ele é essencialmente anterior. O que garante sua anterioridade é o fato de se produzir, no intelecto, a partir de um inteligível que se encontra no intelecto agente, sendo este anterior e mais perfeito que o intelecto humano.

19 Sobre a origem do termo médio, ele é emanado a partir do intelecto agente. Há uma relação de causalidade entre o intelecto agente e o intelecto humano na medida em que aquele, no "K. al-nafs" V.5, é apontado como causa da atualização das formas no intelecto humano. Contudo, não me dedicarei a esta relação do ponto de vista do intelecto agente, pois este artigo parte do princípio de que o conhecimento é uma produção humana e não uma recepção passiva de formas. Ainda que o intelecto intua os termos médios do intelecto agente, a ação de intuir é própria do homem, enquanto a ação de emanar é própria dos intelectos celestes, dentre eles o intelecto agente. Na medida em que a emanação ou fluxo das formas está sempre acontecendo, é necessário que o intelecto humano se volte para esse fluxo e, com a ajuda do termo médio, complete a estrutura silogística peculiar ao conhecimento. 
(Avicena, "K. al-nafs", V.6, p. 249). São estas as poucas considerações feitas por Avicena no "Kitāb al-nafs" acerca da intuição.

Como reconhece Gutas (2001, p. 14), as duas alternativas mencionadas anteriormente podem ser reduzidas a um único processo na medida em que os primeiros professores não foram ensinados, mas intuíram os termos médios sem que um outro homem conduzisse o raciocínio. Deste modo, embora alguns homens obtenham dos seus mestres os termos que ocuparão a posição média do silogismo, o fato de a origem destes termos ser a intuição permite considerá-la como anterior ao aprendizado. Trata-se, portanto, da "disposição poderosa" do intelecto, cujo grau mais elevado é caracterizado pelo intelecto não precisar da conceitualização e do assentimento para conhecer; sua fase de intelecto material ${ }^{20}$ corresponde ao conhecimento em ato.

Contudo, Avicena não atribui este tipo de intuição a todos os homens, mas ele se aplica apenas àqueles que conhecem imediatamente com a aquisição dos termos médios, quando o intelecto material é chamado de intelecto sagrado ( 'aql quds $\vec{\imath}$ ); ${ }^{21}$ trata-se do indivíduo capaz de descobrir o termo médio instantaneamente e sem a mediação do pensamento, a cujo intelecto é atribuído o termo intelecto sagaz (dhak $\left.\bar{a}^{\prime}\right) .{ }^{22} \mathrm{O}$ profeta ${ }^{23}$ é um dos exemplos de intelecto sagaz dada a sua habilidade para adquirir todos os inteligíveis.

[...] de modo breve, a versão padrão é a que se segue. Todo conhecimento inteligível, isto é, todo conhecimento não a priori dos universais que depende do raciocínio silogístico é acompanhado pelo descobrimento do termo médio em um silogismo. O termo médio pode ser adquirido de dois modos, pelo aprendizado ou pela intuição, a qual é um movimento da mente de modo a adquirir espontaneamente o termo médio. No limite, o aprendizado é redutível à intuição na medida em que o primeiro mestre, o qual não foi instruído por ninguém, necessariamente descobriu o termo médio por sua intuição. Assim, todo conhecimento inteligível é adquirido apenas por intuição. (Gutas, 2001, p. 14)

A análise de Gutas exposta na passagem mencionada corrobora com a interpretação proposta segundo a qual a aquisição do termo médio é acompanhada pelo raciocínio silogístico. ${ }^{24}$ Seu raciocínio pode ser divido em

20 Sobre as fases do intelecto cf. M. Secti, 2006, pp. 7-28.

21 Segundo Sebti (2006, pp. 7-28), este grau do intelecto humano não é um quinto grau do intelecto (os quatro graus são intelecto material, em hábito, em ato e adquirido), mas um momento do intelecto de alguns homens caracterizado pela plena capacidade de receber inteligíveis do intelecto agente de modo instantâneo e sem ter que realizar uma preparação para tal.

22 Cf. A. M. Goichon, 1938, §262, p. 132.

23 Sobre a profecia na teoria de Avicena cf. D. N. Hasse, 2000, pp. 154-65.

24 Uma outra passagem que Gutas traduz aponta para a relação entre pensamento e intuição: "pensamento (fikr) às vezes intui (tahdisu) a verdade e discerne o bom, mas ambos variam com respeito ao aumento e ao decréscimo. Todos são acompanhados pela intuição do termo médio sem instrução (ta'iim). Não 
duas etapas, uma cuja conclusão é: o conhecimento inteligível é realizado por intuição e por aprendizado; a segunda, cuja conclusão é: o conhecimento inteligível se reduz à intuição. A primeira etapa pode ser assim reformulada: o conhecimento inteligível é realizado pela aquisição do termo médio; a aquisição do termo médio é realizada por intuição e aprendizado; logo, o conhecimento inteligível é realizado por intuição e aprendizado. A segunda etapa pode ser assim reformulada: o conhecimento inteligível é obtido por intuição e aprendizado; o aprendizado se reduz à intuição; logo, o conhecimento inteligível é obtido por intuição.

O problema da interpretação de Gutas vincula-se à conclusão da segunda etapa; da afirmação de que o conhecimento não se reduz à intuição do termo médio, decorre que a intuição sozinha não produz conhecimento, mas participa da sua produção. ${ }^{25}$ Argumentarei em favor desta interpretação a partir da descrição de como ocorre a chegada ao conhecimento.

Conforme a passagem da seção V.1, "a chegada ao conhecimento acontece por assentimento e conceitualização a partir das [coisas] inteligíveis conhecidas" (Avicena, "K. al-nafs", V.1, p. 206). Portanto, o conhecimento envolve tanto a aquisição das intenções como também o assentimento às proposições que são formuladas acerca destes termos. Retornando ao exemplo da proposição "Zayd é animal", a fim de verificar a sua verdade ou falsidade, é necessário que o intelecto, com a ajuda dos sentidos internos, já tenha conceitualizado as intenções "Zayd" e "animal". Agora, ele é capaz de ordenar os termos na proposição “Zayd é animal”. É esta primeira etapa que o prepara para intuir o termo ("homem") que ocupará a posição média da proposição, o qual é a causa formal da conexão entre o termo menor "Zayd" e o termo maior "animal" na medida em que ele diz o que Zayd é. Após intuir o termo médio (ou tendo sido ensinado por um professor), as outras premissas do silogismo podem ser articuladas: "Zayd é homem" e "todo homem é animal".

Se se excluem os extremos que Avicena descreve em V.6 ("K. al-nafs", V.6, pp. 248-9) e o caso do intelecto sagrado, pode-se dizer que, no caso da maior parte dos homens, a intuição se combina com a formulação do silogismo. ${ }^{26}$

é impossível, contudo, que uma das almas que brilha com a faculdade sagrada esteja constantemente intuindo coisas devido ao seu intenso contato com o intelecto agente [...]". Avicena, "Al-hidāya", pp. 293-4. Apud D. Gutas, 2001, p. 5.

25 Meu raciocínio pode ser assim reformulado: a intuição é a aquisição do termo médio do silogismo. A aquisição do termo médio do silogismo participa da produção do conhecimento. Logo, a intuição participa da produção do conhecimento.

26 Em algumas passagens Avicena vincula a intuição ao silogismo: "Sem dúvida, se as coisas conhecidas pela intuição foram descobertas pelos mestres destas intuições [e] depois as transmitiram aos seus aprendizes, então, é possível que aconteça ao homem a intuição por si mesmo e que articule o silogismo na sua mente sem professor" (Avicena, "K. al-nafs", V.6, p. 249). 
Algumas passagens indicam que, à exceção do profeta, a aquisição do termo médio não resulta em conhecimento imediato. Como a própria expressão "termo médio do silogismo" sugere, o intelecto precisa dos termos menor e maior para que o silogismo se complete. Caso o conhecimento se reduzisse à aquisição do termo médio do silogismo, ${ }^{27} \mathrm{o}$ intelecto apenas conheceria "homem" e seria incapaz de unificar a multiplicidade e multiplicar a unidade, ou seja, seria incapaz de conhecer que "Zayd é homem" e "todo homem é animal", pois ele não teria conceitualizado, a partir das formas sensíveis, as intenções universais "Zayd" e "animal".

\section{II}

Porque o termo médio é parte de um silogismo resultante em conhecimento, a continuação do raciocínio silogístico iniciado com a conceitualização dos particulares não acontece sem a intuição destes termos médios. Hasse (2000, p. 181) propõe uma análise da função que eles exercem a partir do silogismo mencionado por Avicena no "Kitāb al-burhan" ("Livro das demonstrações"), cuja origem se remonta a Aristóteles ("K. al-burhan”, 89b11).

Intuição é o movimento desta faculdade em direção à aquisição do termo médio por si mesmo. Por exemplo, se uma pessoa vê a lua e que ela apenas brilha, segundo às suas fases, do lado voltado para o sol, então, sua mente, pela intuição, obtém o termo médio que é: a causa da lua brilhar é o sol. (Avicena, "Kitāb al-burhan", p. 259. Apud Hasse, 2000, p. 181)

Hasse reconstrói o silogismo mencionado na passagem anterior do seguinte modo: tudo cuja causa da luz é o sol brilha apenas do lado voltado para o sol. A lua possui o sol como causa da sua luz; logo, a lua brilha apenas do lado voltado para o sol. Neste caso, o termo médio "possuir o sol como causa da luz" fornece a causa real do evento descrito na conclusão. No entanto, há uma distinção entre a ordem da enunciação do silogismo e a ordem da sua descoberta. ${ }^{28} \mathrm{O}$ intelecto não parte da conclusão universal

27 Arif considera que a intuição produz conhecimento intuitivo, o qual é um dos sentidos que ele atribui ao termo. Os sinônimos de ḥads são: ma 'rif, mulāhaẓa, ișābah, yaqụah, fahm, taḥqīq, tahșịn, iqtināṣ, fațān e fițn. Nas suas palavras: "para intuição no primeiro sentido, isto é, como uma faculdade mental da cognição, Ibn Sina usa alguns termos familiares como intelecto ou razão ('aql), faculdade inata (fițra), mente (khirad) e aptidão mental (quwwat al-nafs). Michot descreve intuição como a capacidade de possuir conhecimento sem recebê-lo de um mestre ou por reflexão, "est un fait d'experience". Cf. S. Arif, 2000, pp. 99-100; J. R. Michot, 1986, p. 83, nota 91.

28 Em 94b22-36, Aristóteles afirma que o silogismo procede disto que foi adquirido por último mesmo se o seu princípio são as coisas adquiridas primeiro. 
"tudo cuja causa da luz é o sol brilha apenas do lado voltado para o sol", mas da premissa empírica "a lua brilha apenas do lado voltado para o sol". Caso contrário, o conhecimento que resulta do silogismo não seria universal, mas particular visto que a conclusão reconstruída por Hasse é "a lua brilha apenas do lado voltado para o sol". Para que isto fique mais claro, cabe compreender a distinção proposta por Avicena em V.5 entre dois momentos do conhecimento: a unificação da multiplicidade e a multiplicação da unidade.

[...] quando [a alma] se volta para aquelas formas imaginadas e chega nela a luz do intelecto agente por um tipo de conjunção, elas são preparadas de modo que se originem nela, a partir da luz do intelecto agente, as abstrações destas formas das misturas. Logo, as coisas essenciais são distinguidas, pelo intelecto, dos acidentes e do que, nestas coisas imaginadas, assemelham-se e se diferenciam. As intenções, as quais não se diferenciam nestas [coisas] vêm a ser uma intenção única na essência do intelecto por meio de comparação entre as [suas] semelhanças. Contudo, [as intenções] que estão [nas coisas imaginadas] vêm a ser múltiplas devido à comparação entre as diferenças. $\mathrm{O}$ intelecto possui a capacidade de multiplicar a unidade e de unificar a multiplicidade no caso das intenções. A ação de unificar o múltiplo acontece sob dois aspectos: o primeiro no qual as intenções múltiplas se tornam diferenciadas em número na imaginativa; quando não se diferenciam com respeito à definição, trata-se de uma única intenção. No segundo aspecto, a partir das [diferentes] intenções dos gêneros e das diferenças, uma única intenção é composta através da [formulação da] definição. A [ação de multiplicar o uno] é contrária a estes dois aspectos e isto está entre as propriedades do intelecto humano, mas não pertence às outras faculdades que percebem o múltiplo enquanto múltiplo nem [percebem] a unidade enquanto una. Não é possível que elas percebam a unidade simples, mas [apenas] a unidade da perspectiva segundo a qual ela é um todo composto de coisas e de seus acidentes. Não é possível que [as faculdades] separem o que é acidental e o remova do que é essencial. (Avicena, “K. al-nafs", V.5, p. 236)

A partir da afirmação "o intelecto possui a capacidade de multiplicar a unidade e de unificar a multiplicidade no caso das intenções", Avicena distingue dois momentos: um quando "as intenções, as quais não se diferenciam nestas [coisas], vêm a ser uma única intenção na essência do intelecto por meio de comparação entre as [suas] semelhanças" e outro quando o intelecto, por si, é capaz de multiplicar o termo médio.

A ação de unificar o múltiplo acontece no momento em que as diferentes formas particulares não distinguem entre si com respeito à descrição e, por isto, tornam-se uma única intenção como, por exemplo, quando se agrupa Zayd e "Amr na mesma intenção "mortal" ou "animal" ou quando o intelecto agrupa diferentes intenções em uma única intenção que não pode ser reduzida a nenhuma das intenções anteriores como, por exemplo, "animal" e "que ri" na descrição de "homem", o qual não pode ser reduzido a "animal" ou “que ri”. É com a ajuda das faculdades cogitativa e estimativa que o intelecto 
unifica a multiplicidade em intenções ou universais simples. Somente após a conceitualização dos particulares, as suas definições podem ser comparadas e eles agrupados sob a mesma intenção.

No caso de multiplicar a unidade, trata-se da atividade exclusiva do intelecto dado que somente ele lida com os termos médios e com as intenções universais. Na medida em que os sentidos internos não percebem a unidade simples ou a humanidade, mas apenas a "unidade da perspectiva segundo a qual ela é um todo composto de acidentes" como, por exemplo, Zayd ou "Amr, "não é possível que [os sentidos] separem o que é acidental e o remova do que é essencial" nem que eles construam uma premissa tal como "Todo homem é animal" ou "Tudo cuja causa da luz é o sol brilha apenas do lado voltado para o sol". Nestes casos, as intenções conceitualizadas (animal/brilhar apenas do lado voltado para o sol) são atribuídas ao termo médio do silogismo adquirido por intuição (homem/ter o sol como causa da luz). Na medida em que a intenção está diretamente vinculada aos particulares, uma vez tendo sido apreendida a partir deles, os termos médios podem ser, inequivocamente, atribuídos a cada um dos particulares. Igualmente se diz que Zayd, 'Amr, João, Sócrates etc. são homens. Neste sentido, a unidade representada pelo termo médio é multiplicada.

Deste modo, pode-se considerar que Avicena ("K. al-nafs", V.5, p. 236) descreve como o conhecimento produzido pelo pensamento acontece a partir de duas grandes etapas: a unificação da multiplicidade por ordenação dos particulares semelhantes em uma única descrição e a aplicação do universal adquirido a diferentes particulares da mesma espécie, ou seja, a multiplicação da unidade.

Mesmo diante desta descrição das etapas do conhecimento, há uma certa dificuldade em estabelecer o exato momento no qual o intelecto se desocupa dos sentidos internos, principalmente das faculdades cogitativa e estimativa, e age por si mesmo. Contrariando a interpretação ${ }^{29}$ segundo a qual todas as fases do pensamento são realizadas pelo intelecto em conjunto com a faculdade cogitativa, algumas passagens ${ }^{30}$ parecem indicar que é na fase (martaba) de intelecto adquirido, quando o intelecto não mais se vale dos sentidos. Deste modo, não se trata de o "intelecto já estar, por definição, envolvido nas operações da faculdade cogitativa" (Black, 2013, p. 72), mas é a imaginação cogitativa que está envolvida nas operações do intelecto. É ele que a utiliza em uma determinada etapa do ato de conhecer, não o contrário, 
pois o conhecimento ( 'ilm) é atividade própria do intelecto teorético, não de um sentido interno.

O primeiro argumento contra a interpretação de a cogitativa conhecer pelo pensamento e que ele é uma atividade conjunta entre ela e o intelecto fundamenta-se na natureza do pensamento. Considera-se que as "operações do pensamento discursivo" são "análise e síntese” (Black, 2013, p. 72) e tendo em vista que é função da imaginação cogitativa compor formas, conclui-se que o pensamento é realizado pela imaginação cogitativa que "tem um tipo de acesso aos inteligíveis universais" (Black, 2013, p. 69) e é capaz de os compor. No entanto, são dois os grandes problemas desta formulação. O primeiro diz respeito ao fato de a cogitativa não lidar com formas inteligíveis, mas apenas com as materiais.

Avicena ("K. al-nafs", V.2, pp. 211-4) ${ }^{31}$ apresenta um argumento contra o fato de o substrato dos inteligíveis ser um corpo ou uma dimensão entre as dimensões. ${ }^{32}$ Tendo em vista as considerações avicenianas contra o fato de os inteligíveis possuírem como substrato uma faculdade corpórea e considerando que a faculdade cogitativa está "localizada na concavidade central do cérebro" (Avicena, “K. al-nafs", I.5, p. 45), nenhuma forma universal é objeto próprio de um sentido interno, mas do intelecto, a faculdade incorpórea. ${ }^{33}$ Assim, do mesmo modo que Avicena utiliza a natureza das formas materiais e das intenções sensíveis como critério para a distinção entre os sentidos internos, ${ }^{34}$ aqui, a natureza dos inteligíveis também é utilizada como critério para diferenciar o intelecto das outras faculdades.

O segundo problema põe-se em vista do modo pelo qual o pensamento é realizado. Como foi visto, o conhecimento produzido pelo pensamento pressupõe conceitualização e assentimento. ${ }^{35}$ Não há dúvidas acerca da participação da cogitativa e da estimativa na conceitualização dos particulares. ${ }^{36}$ Contudo, Avicena é claro sobre a exclusão da participação dos sentidos na multiplicação da unidade: "a [ação de multiplicar a unidade] é contrária a estes dois aspectos e isto está entre as propriedades do intelecto, mas não pertence às outras faculdades que percebem a multiplicidade [enquanto] multiplicidade" (Avicena, "K. al-nafs", V.5, p. 235). Em V.3, após

31 Cf. J. McGinnis, 2010, p. 255.

32 Cf. Avicena, "K. al-nafs", V.2, pp. 211-4; J. McGinnis, 2010, p. 255.

33 Segundo Avicena ("K. al-nafs", V.2, p. 214): "as formas inteligíveis são obtidas por nós [através de uma] substância incorpórea".

34 Cf. "K. al-nafs", I.5, pp. 42-3.

35 Cf. Avicena, "Le livre de science", p. 21.

36 Cf. Avicena, "K. al-nafs", V.3, pp. 221-2. 
explicitar os modos pelos quais os sentidos auxiliam o intelecto, Avicena ressalta que, depois de ser auxiliado pelo corpo na aquisição dos princípios da conceitualização e do assentimento, ele "retorna a si" (Avicena, "K. alnafs", V.3, p. 222). Assim, a "ajuda e emprego da imaginação e da estimativa" (idem) não fornecem elementos suficientes para concluir que o pensamento se reduz à ação de qualquer uma delas.

Há uma distinção entre a ordenação que a substância incorpórea realiza das intenções universais e a ordenação que a imaginação realiza, ${ }^{37}$ corroborando o fato de ser o intelecto que lida com inteligíveis:

Por exemplo, quando você divide as intenções dos termos indicados pela expressão "Todo homem é animal" [que está] presente na sua alma, você descobre que a intenção de cada um [dos termos] não é conceitualizada exceto pela substância incorpórea e descobre que é próprio [da conceitualização realizada por esta substância incorpórea colocar umas intenções] antes e [outras] depois. Se você rearranja esta [expressão] de modo que a ordem das intenções conceitualizadas é a ordem oposta da expressão "animal é predicado de todos os homens" não duvida que esta ordem, sendo a ordem das intenções universais, apenas é ordenada pela substância incorpórea. De certo ponto de vista, ela também é ordenada pela imaginação como [algo] perceptível, não como inteligível. Assim, as duas ordenações são diferentes e o inteligível simples [está relacionado] à primeira [ordenação] (Avicena, "K. al-nafs", V.6, p. 241).

Avicena menciona que as intenções dos termos da proposição "Todo homem é animal" somente são conceitualizadas pelo intelecto. Embora esta afirmação não seja justificada aqui, uma das suas características é o fato de o intelecto colocar "[umas intenções] antes e outras depois" (Avicena, "K. al-nafs", V.6, p. 241). A diferença entre a ordenação intelectual e a ordenação imaginativa é o tipo de coisa que é ordenado: coisas inteligíveis ou coisas sensíveis. Assim, a passagem estabelece uma distinção radical entre a ordenação do que é percebido pelos sentidos, no caso, pela imaginação, e a ordenação realizada pelo intelecto. Deste modo, ainda que Avicena use a imaginação em sentido genérico, há uma diferença na ordenação que ela e o intelecto realizam.

37 Segundo Black, "em sentido estrito, para Avicena, não existe nenhuma composição e divisão real dos universais exceto acidentalmente em virtude da atividade concomitante da imaginação". Contudo como será exposto, em V.6, Avicena atribui ao intelecto a atividade de compor e ordenar diferentemente da atividade de compor e ordenar da imaginação (Cf. D. Black, 2013, p. 72). 
Meu segundo argumento contra o pensamento ser a atividade própria da faculdade cogitativa e em favor de ser uma atividade própria do intelecto baseia-se na natureza do intelecto. Aqui tenho em mente a sua independência das faculdades do corpo e as fases pelas quais ele passa até chegar ao conhecimento em ato.

Diferentemente do intelecto prático que necessita "do corpo e das faculdades corpóreas" (Avicena, "K. al-nafs", V.1, p. 208) para realizar "todas as suas ações" (idem), o intelecto teorético, por ser uma "substância independente" (idem), "é capaz de agir por si mesmo" (idem), tendo sua ação própria determinada por "um primeiro propósito (bi-al-qasd al-awwal)" (Avicena, "K. al-nafs", I.4, p. 36).

São quatro os argumentos apresentados em V.2 (Avicena, "K. al-nafs", V.2, pp. 109-130) na defesa da imaterialidade e independência do intelecto de qualquer substrato corpóreo: a natureza dos inteligíveis, o fato de os inteligíveis serem infinitos em potência, a autointelecção realizada pelo intelecto (constatada pelo experimento mental do homem suspenso no ar, o qual não é um argumento, mas o reconhecimento da independência da alma e da sua substancialidade $)^{38}$ e o fato de as faculdades corpóreas se fatigarem com o uso. É estranho considerar que o intelecto dependa completamente da cogitativa para pensar ainda que todos estes argumentos apontem a sua independência com respeito a qualquer faculdade corpórea.

Assim, assumindo a independência do intelecto e o fato de ele possuir uma ação própria, ${ }^{39}$ cabe investigar sob qual critério esta ação é determinada. A partir dos princípios de diferenciação das faculdades da $a l m a,{ }^{40}$ mais especificamente, do princípio que se baseia no primeiro propósito, ou intelecto e cogitativa possuem ações diferentes ou as duas faculdades realizam a mesma ação própria. Caso se assuma a segunda alternativa, infringe-se o princípio

38 Segundo Avicena ("K. al-nafs", V.2, pp. 216-7): "Dizemos, pois que se a faculdade intelectual inteligisse por meio de um órgão corpóreo, de modo que sua ação própria somente se completasse por meio do emprego desse órgão corpóreo, então, seria necessário que ela não inteligisse a si mesma, que ela não inteligisse o órgão e que ela não inteligisse que inteligiu; não há um órgão entre ela e sua essência, não há um órgão entre ela e seu órgão e não há um órgão entre ela e o que ela inteligiu. Em vez disso, ela intelige a si mesma, intelige o órgão que se alegaria que ela possui e ela intelige que inteligiu. Portanto, ela intelige por si mesma e não por meio de um órgão, mas isso já estabelecemos".

39 Segundo Avicena ("K. al-nafs", V.1, p. 208): "[...] a alma [humana] é uma coisa que possui estas duas faculdades e é uma substância independente, conforme foi esclarecido, que possui uma disposição para as ações. Algumas [ações] não se realizam senão por meio dos órgãos e, como regra, pela proximidade deles, de um modo geral; outras têm alguma necessidade dos órgãos e outras definitivamente não necessitam deles. Tudo isto será explicado depois. A substância da alma humana está disposta para obter um tipo de perfeição por si mesma, pois o que é superior não necessita do que é inferior nela. Esta disposição que pertence a ela deve-se a uma coisa chamada intelecto teorético".

40 Avicena, "K. al-nafs", I.4, p. 36. 
segundo o qual "cada faculdade, por essência e fundamento é princípio para uma determinada ação" (idem); infringe-se, ainda, um segundo princípio de diferenciação, ${ }^{41}$ cuja distinção entre o intelecto e os sentidos internos fundase no fato de apenas o intelecto abstrair completamente a forma material das qualidades sensíveis.

Deste modo, assumir que ambos realizam a mesma ação infringe dois dos critérios de classificação das faculdades da alma apresentados em I.4 e II.2, um que se baseia no primeiro propósito e o outro no grau de abstração das formas.

Em várias passagens do "Kitāb al-nafs", ${ }^{42}$ depara-se com um momento no qual o intelecto isola-se das outras faculdades. A ideia comum é que, após ter adquirido os primeiros princípios da conceitualização, o intelecto "retorna para si" (Avicena, "K. al-nafs", V.3, p. 222) ou "isola-se em suas ações" (Avicena, "K. al-nafs", V3, p. 223). Assim, há um momento no qual ele não precisa mais do auxílio de nenhum dos sentidos, nem mesmo da cogitativa, para conhecer. Este momento é a fase de intelecto adquirido, quando o intelecto já conceitualizou os particulares e apenas precisa se conectar com o intelecto agente, pois não é necessário conceitualizá-los novamente. Se a única coisa necessária é o intelecto se conectar com o intelecto agente, isto somente se realiza por uma faculdade imaterial.

\begin{abstract}
Nesse caso, o que resulta para [a alma racional], então, é um intelecto adquirido. Tão somente chama-se intelecto adquirido porque, como ficará claro para nós, o intelecto em potência só sai para o ato por causa de uma inteligência que está sempre em ato por uma espécie de ligação que imprime nele formas adquiridas à partir do que lhe é extrínseco. Além do mais, esses são os graus das faculdades que se chamam intelectos teoréticos e, quando do intelecto adquirido, completa-se o gênero animal e, a partir dele, a espécie humana. Lá, a faculdade humana já assimilou os princípios primeiros da existência em sua totalidade. (Avicena, "K. al-nafs", I.5, p. 50)
\end{abstract}

É imprescindível, a fim de o intelecto chegar ao grau de intelecto adquirido, já ter conceitualizado os "primeiros princípios" (idem) e se voltar para a causa da sua atualização, o intelecto agente. ${ }^{43}$ Deste modo, as formas adquiridas são impressas no intelecto após ele já ter "assimilado os princípios primeiros da existência em sua totalidade" (idem).

41 Avicena, "K. al-nafs", II.2, p. 58.

42 Segundo Avicena (“K. al-nafs”, V.3, p. 223; V.5, p. 238): “Quando a alma [racional] é aperfeiçoada e fortificada, em qualquer circunstância, ela isola-se em suas ações ainda que as faculdades sensíveis, imaginativa e as outras faculdades corpóreas desviem-na de sua ação".

43 Avicena, "K. al-nafs", V.5, pp. 234-5. 


\section{III}

A partir da argumentação exposta, conclui-se que há um tipo de conhecimento teorético produzido pelo pensamento e pela intuição dos termos médios. O outro tipo de conhecimento, dito simples, é entendido como a descoberta instantânea dos primeiros princípios, cuja especificidade, no "Kitāb al-nafs", é se realizar sem ordenação ou composição.

$\mathrm{O}$ conhecimento produz-se pelo pensamento quando o intelecto unifica a multiplicidade a partir das formas particulares e multiplica a unidade. Em vista dos exemplos de silogismo analisados, este conhecimento não se reduz à ordenação e composição das intenções com emprego dos sentidos internos nem à intuição dos termos médios. Ele possui uma estrutura silogística cujas premissas são compostas do termo menor e maior, que são conceitualizados, e do termo médio recebido a partir do intelecto agente.

Ao afirmar que o intelecto conhece por conceitualização e assentimento, Avicena especifica melhor o sentido de dizer que a faculdade racional abstrai por completo as formas materiais. A abstração mostrou-se insuficiente para a compreensão dos momentos que compõem o conhecimento em vista da aquisição dos termos do silogismo. Por isto, a conceitualização apresentase como requisito fundamental para a apreensão das intenções universais, possibilitando ao intelecto formular, a partir delas, proposições empíricas a serem assentidas.

Deste modo, a redução do conhecimento à intuição dos termos médios ou à ação de combinar formas realizada pela cogitativa não são coerentes com a epistemologia aviceniana no "Kitāb al-nafs". A consequência de assumir a primeira posição é a aniquilação da estrutura proposicional do conhecimento a não ser que se assuma ou que os outros termos do silogismo também são intuídos como, por exemplo, Zayd no silogismo "todo homem é mortal, Zayd é homem, logo, Zayd é mortal", ${ }^{44}$ ou que a intuição se combina com a conceitualização e o assentimento, isto é, com o pensamento. ${ }^{45}$

44 Esta opção parece contrariar a ontologia das formas em Avicena, pois o intelecto não lida com formas materiais devido às qualidades sensíveis que as acompanham.

45 Gutas (2012, pp. 420-1), em um artigo mais recente, parece concordar que a intuição se combina com o pensamento: "[...] isto significa que todos os inteligíveis que servem como termos médios e que dependem do silogismo para serem construídos também existem nos intelectos celestes [...]. Desde que todos os termos médios venham do intelecto agente, a questão é como os homens podem ter acesso a eles ou como a intuição, i.e., guessing them, precisamente funciona. Avicena inicialmente mantém que todo aprendizado, i.e., toda aquisição de termos médios, é acompanhada ou por instrução ou por intuição; mas tendo concluído que a instrução ultimamente também depende da intuição, ele introduziu a reflexão; reflexão e pensamento, baseado na abstração e na análise lógica, preparam o intelecto para a intuição, i.e., para alcançar o termo médio ou recebê-lo do intelecto agente [...]. Resumindo o processo intelectivo, o dispositional intellect em posse dos inteligíveis primeiros e após o processo de raciocínio envolvendo a 
A natureza dos inteligíveis e do intelecto, marcadas pela imaterialidade, e a independência de uma faculdade corpórea apontam para a existência de uma ação que exclusivamente pertence ao intelecto. Por mais que as faculdades cogitativa e estimativa colaborem com ele, sua ação de construir silogismos e chegar a um novo conhecimento a partir do que já foi conhecido, ou seja, os princípios, não se reduz à composição de formas sensíveis. Portanto, algumas passagens do "Kitāb al-nafs" parecem indicar que a interpretação do pensamento como uma ação própria da faculdade cogitativa contraria não apenas os critérios de classificação das faculdades como também as fases envolvidas no ato de pensar, o qual não se reduz à conceitualização das formas pela imaginação. Nem mesmo se Avicena reduzisse o pensamento à ordenação de inteligíveis, ele seria realizado pela cogitativa, pois os inteligíveis não são objeto de uma faculdade corpórea.

\section{Referências}

ARISTOTÉLES. "Kitāb al-burhan”. In: A. Badawi, 1952.

AVICENNA. "Book of Demonstrations" III.5. In: J. McGinnis; D. Reisman (transl.), 2007, p. 152-5.

AVICENA. "Kitāb al-nafs". Ed. Rahman. New York: Oxford University Press, 1959. "Kitāb al-burhan". Ed. By Abu Ela 'Afífí. Cairo: L'Organisation Egyptienne Generale du Livre, 1956.

"Le livre de science". Trad. M. Achena et H. Massé. Paris: Les Belles Lettres/Unesco, 1986.

"Libro della Guarigione". Trad. A. Bertolacci. Torino: UTET, 2008.

ADAMSON, P (ed.). "Interpeting Avicenna". New York: Cambridge University Press, 2013.

ARIF, S. "Intuition and its Role in Ibn Sina's Epistemology". Journal of the International Institute of Islamic Thought and Civilization, Vol. 5, Nr. 1, 2000.

ALWISHAH, A. R. D. "Avicenna's Philosophy of Mind: Self-awareness and Intentionality". Ph.D., University of California, Los Angeles, 2006.

ARNALDEZ, R. "Un precedent avicennien du Cogito cartesien?" Annales Islamologiques, 11, 1972.

BADAWI, A. (ed.). "Mantiq Aristu”. Transl. Abu Bishr Matta Ibn Yunus. Cairo, Vol. $1,1952$.

BERTOLACCI, A. "Avicenna and Averroes on the Proof of God's Existence and the Subject-Matter of Metaphysics". Medioevo, 32, 2007. 
BLACK, D. "Arabic Theories of Intentionality and their Impact in the Latin West". Workshop on Later Medieval Perspectives on Intentionality, University of Parma, Jun. 10, 2009.

BLACK, D. "Avicenna on Individuation, Self-Awareness, and God's Knowledge of Particulars". In: R. Taylor, I. Omar (eds.), 2012, pp. 255-81.

BLACK, D. "Avicenna on Self-Awareness and Knowing that One Knows". In: Rahman, Street, Tahiri (eds.), 2008, pp. 63-87.

BLACK, D. "Estimation in Avicenna: The Logical and Psychological Dimensions". Dialogue, XXXII, 1993.

BLACK, D. "Estimation and Imagination: Western Divergences from an Arabic Paradigm". Topoi, 19, 2000.

BLACK, D. "Imagination, Particular Reason and Memory. The role of the Internal Senses in Human Cognition". Workshop on Varieties of Cognitive Theory in the Later Middle Ages: Towards a Status Quaestionis, Katholieke Universiteit Leuven, Feb. 19, 2010.

BLACK, D. "Intentionality in Medieval Arabic Philosophy". Quaestio, Vol. 10, 2010. BLACK, D. "Knowledge ('ilm) and Certitude (yaqin) in al-Farabi's Epistemology". Arabic Sciences and Philosophy, 16.1, 2006.

BLACK, D. "Rational Imagination: Avicenna on the Cogitative Power". In: J. Tellkamp, X. F. López (eds.), 2013, pp. 59-81.

BROWN. “Aquinas' Missing Flying Man”. Sophia, 40, 1, 2000.

DAVIDSON, H. "Alfarabi, Avicenna and Averroes on Intellect”. New York: Oxford University Press, 1992.

DI MARTINO, C. “Ma'ān̄̄/Intentiones et Sensibilitè par accident”. In: M. C. Pacheco, J. F. Meirinhos (eds.), 2006, pp. 507-521.

DI MARTINO, C. "Ratio Particularis, Doctrines des sens internes d'Avicenne à Thomas d'Aquin". France: Librairie Philosophique, 2008.

GOICHON, A. M. "Lexique de la Langue Philosophique d'Ibn Sina". Paris: Desclée de Brower, 1938.

GUTAS, D. "Avicenna and the Aristotelian Tradition". New York, Leiden, Copenhagen, Colongne: Brill, 2013 [1988].

GUTAS, D. "Intuition and Thinking: The Evolving Structure of Avicenna's Epistemology". In: R. Wisnovisky (ed.), 2001, pp. 1-38.

GUTAS, D. "Avicenna: The Metaphysics of the Rational Soul". The Muslim World, Vol. 102, pp. 417-25, 2012.

GUTAS, D. "The Empiricism of Avicenna". Oriens, Vol. 40, pp. 391-436, 2012.

HALL, R. E. “The wahm in Ibn Sina's Psychology”. In: M. C. Pacheco, J. F. Meirinhos (eds.), 2006, pp. 533-549.

HASSE, D. N. “Avicenna's De anima in the Latin West". London: Warburg Institute, Turin: Nino Aragno, 2000.

HASSE, D. N. “Avicenna's Epistemological Optimism”. In: P. Adamson (ed.), pp. 109-119, 2013. 
JANSSENS, J. L. "Experience (tajriba) in Classical Arabic Philosophy (al-FarabiAvicenna)". Quaestio, 4, 2004.

MARMURA, M. “Avicenna's 'Flying Man in Context”. Monist, 69, 1986.

MICHOT, J. R. "La Destinee de l'homme selon Avicenne”. Lovanii: Peeters, 1986.

MCGINNIS, J. “Avicenna”. New York: Oxford University Press, 2010.

MCGINNIS, J. "Scientific Methodologies in Medieval Islam”. Journal of the History of Philosophy, Vol. 41, Nr. 3, 2003.

MCGINNIS, J. "Logic and Science: The role of Genus and Difference in Avicenna's Logic, Science and Natural Philosophy". Documenti e Studi sulla Filosofia Medievale, XVIII, pp. 165-86, 2007.

MCGINNIS, J.; REISMAN, D. (transl.). "Classical Arabic Philosophy. An Antology of Sources". Indianapolis/Cambridge: Hackett Publishing Company, Inc., 2007.

MOREWEDGE (ed.). "Neoplatonism and Islamic Thought". Albany: State University of New York Press, 1992.

PACHECO, M. C; MEIRINHOS, J. F (eds.). "Intellect et Imagination dans la Philosophie Médiévale". Actes du XI ${ }^{\mathrm{e}}$ Congrès International de Philosophie Médiévale de la Societè Internationale pour l'Étude de la Philosophie Médiévale (S.I.E.P.M). Porto. Turnhout: Brepols, 2006.

RAHMAN; STREET; TAHIRI (eds.). "The Unity of Science in the Arabic Tradition". Dordrecht: Springer Science, 2008.

SEBTI, M. “Avicenne. L'âme humaine”. Paris: PUF, 2000.

SEBTI, M. "L'Analogie de la lumière dans la noétique d'Avicenne". Archives d'Histoire Doctrinale et Littéraire du Moyen Âge, 73, 2006.

TAYLOR, R., OMAR, I. (eds.). "The Judeo-Christian-Islamic Heritage: Philosophical and Theological Perspectives". Milwaukee: Marquette University Press, 2012.

TELLKAMP, J.; LÓPEZ, X. F. (eds.). "Philosophical Psychology in Medieval Arabic and Latin Aristotelianism". Paris: J. Vrin, 2013.

TWERSKY; WILLIAMS (eds.). "Studies in the History and Philosophy of Religion". Cambridge: Harvard University Press, 1973.

WESTRA, S. "Self-knowledge in Plato, Plotinus, and Avicenna". In: Morewedge (ed.), 1992, pp. 89-110.

WOLFSON, H. A. "The Internal Senses in Latin, Arabic and Hebrew Philosophic Texts". Harvard Theological Review, Vol. XXVIII, Nr. 2, 1935.

WOLFSON, H. A. "The Terms Tasawwur and Tasdiq in Arabic Philosophy and Their Greek, Latin and Hebrew Equivalents". In: Twersky, Williams (eds.), 1973, pp. 478-92. WISNOVSKY, R (ed.). “Aspects of Avicenna”. Princeton: Princeton Press, 2001. 